\title{
Ações afirmativas e o acesso à UFRGS: subsídios para uma avaliação
}

João Vicente Silva Souza*

\section{Problema de Pesquisa}

Trata-se do projeto de pesquisa Perfis Socioeconômicos dos Vestibulandos da UFRGS: análises comparativas dos periodos anterior e posterior à adoção do Sistema de Reserva de Vagas - cotas, que investiga o impacto da implementação da reserva de vagas (cotas) no vestibular da UFRGS a partir de 2008, sob diversas variáveis socioeconômicas dos vestibulandos da UFRGS, através dos dados fornecidos pela COPERSE/UFRGS. Este projeto tem o apoio do CNPq, através de uma Bolsa de Iniciação Científica de Graduação.

\section{Justificativa}

A Universidade Federal do Rio Grande do Sul instituiu, a partir da Decisão No. 134/2007 do Conselho Universitário, a sua Política de Ações Afirmativas que, dentre outras ações, instituiu o Sistema de Reserva de Vagas (cotas) para alunos de escolas públicas e alunos autodeclarados negros de escolas públicas, bem como a criação de vagas especiais para estudantes indígenas. No ano de 2008, a UFRGS realizou o seu primeiro Concurso Vestibular com Reserva de Vagas, cujos relatórios e estudos recentes encontrados em UFRGS/COPERSE $(2008 ; 2009)$ e Souza (2008;

\footnotetext{
* Professor de Educação Física do Colégio de Aplicação da UFRGS. Doutor em Educação pela UFRGS. E-mail: joao.souza@ufrgs.br
} 
2009) mostraram algumas importantes mudanças em relação a algumas variáveis socioeconômicas ${ }^{1}$ dos vestibulandos inscritos e classificados, quando comparadas às variáveis dos anos anteriores (sem cotas). No entanto, tais dados apresentados são parciais, havendo a necessidade de análises mais abrangentes e complexas, incluindo um maior número de variáveis nas análises, inclusive as diferenças conforme o Curso de Graduação escolhido.

\section{Objetivos}

- Geral: dar conhecimento às comunidades universitárias e científicas dos resultados da política de acesso aos cursos de graduação da UFRGS voltadas aos estudantes de escolas públicas e estudantes negros de escolas públicas no que se refere aos dados socioeconômicos daqueles que procuram e dos que ingressam nesta universidade.

- Específico: dar conhecimento à comunidade da UFRGS sobre os resultados na pesquisa acerca da política de acesso em questão, a fim de contribuir para o processo de avaliação do Programa de Ações Afirmativas da UFRGS a ser realizado em 2012.

\section{Metodologia}

Os dados quantitativos e análises estatísticas a respeito das características sócio-econômicas e de escolarização dos vestibulandos da UFRGS são obtidos das seguintes maneiras:

- através das planilhas eletrônicas fornecidas pela Comissão Permanente de Orientação - COPERSE, contendo os dados dos Questionários Socioeconômicos, preenchidos pelos vestibulandos da UFRGS, dos anos de 2004 a 2011;

Baseadas nas respostas dos Questionários Socioeconômicos respondidas pelos vestibulandos no momento da inscrição para o Concurso Vestibular. 
- através dos dados básicos sobre os Concursos Vestibular publicados na página eletrônica da $\mathrm{COPERSE}^{2}$;

- através dos relatórios do Concurso Vestibular e estudos estatísticos já realizados na UFRGS sobre os perfis socioeconômicos dos vestibulandos da UFRGS, cuja relação é encontrada em Souza $(2008 ; 2009)$.

Para facilitar as análises básicas desses dados (contendo mais de 30.000 questionários em cada ano), os mesmos são transpostos para o programa de análise estatística SPSS - Statistical Package for Social Sciences, disponível aos usuários da UFRGS ${ }^{3}$, contando com a assessoria do Núcleo de Assessoria Estatística (NAE) do Instituto de Matemática da UFRGS.

As análises estatísticas escolhidas são:

- levantamento de variáveis em separado (tabelas de frequência por variável);

- análises multivariadas (tabelas de frequência ou gráficos relacionando três ou mais variáveis);

- apresentação de testes de hipóteses e índices de significância da associação entre variáveis categóricas e de correlação entre variáveis numéricas;

- outras análises estatísticas que porventura sejam recomendadas pelo Núcleo de Assessoria Estatística.

A pesquisa abrange a totalidade dos Vestibulandos da UFRGS, respondentes dos Questionários Socioeconômicos aplicados pela COPERSE/CPD/UFRGS como pré-requisito para a inscrição no Concurso Vestibular, abrangendo o período de 2004 a 2011.

\section{Resultados esperados e impactos}

Os resultados da investigação, os quais serão apresentados em tabelas e gráficos e comentários, apontam que a adoção da

\footnotetext{
Disponível em: http://www.ufrgs.br/coperse

As planilhas são fornecidas pela COPERSE sem a identificação (nome) dos candidatos.
} 
reserva de vagas para estudantes de escolas públicas e estudantes autodeclarados negros de escolas públicas gerou um impacto significativo no ingresso dos mesmos nos cursos de graduação da UFRGS. Por conta destas mudanças, alteram-se também os perfis socioeconômicos dos estudantes que hoje entram na UFRGS através desta ação afirmativa, em comparação com anos anteriores, possibilitando assim incrementar o ingresso de alunos de origem popular, com baixa renda familiar, com pais com pouca escolaridade, etc. Tais diferenças, no entanto, continuam mais ou menos favoráveis aos objetivos de equidade de acesso a esta universidade pública, conforme o curso escolhido. Percebe-se, portanto, que esta política ainda pode avançar, caso se aumente a participação dos alunos da rede pública, o ingresso de alunos negros e haja mais equilíbrio no ingresso nos cursos de maior concorrência.

\section{Referências}

BOURDIEU, Pierre; PASSERON, Jean-Claude. A Reprodução elementos para uma teoria do sistema de ensino. 2 ed. Rio de Janeiro: Zahar, 1977.

BOURDIEU, Pierre. A escola conservadora: as desigualdades frente à escola e à cultura. In: NOGUEIRA, Maria Alice; CATANI, Afrânio (Orgs.). Pierre Bourdieu: escritos de educação. 2 ed. Petrópolis: Vozes, 1998a. p. 39-64.

BRANDÃO, André Augusto (Org.). Cotas raciais no Brasil: a primeira avaliação. Rio de Janeiro: DP\&A, 2007.

RICHARDSON, Roberto Jarry. Pesquisa social: métodos e técnicas. São Paulo: Atlas, 1985.

SOUZA, João Vicente Silva. Vestibulandos da UFRGS: diferenças que produzem desigualdades. In: TETTAMANZY, Ana Lúcia L. et al. (Orgs.). Por uma política de ações afirmativas: problematizações do programa conexões de saberes/UFRGS. Porto Alegre: Ed. UFRGS, 2008. 
SOUZA, João Vicente Silva. Alunos de escola pública na Universidade Federal do Rio Grande do Sul: portas entreabertas. Porto Alegre: UFRGS, 2009. Tese (Doutorado em Educação) - Programa de Pós-Graduação em Educação, Universidade Federal do Rio Grande do Sul. Porto Alegre, 2009.

TETTAMANZY, Ana Lúcia L. et al. (Orgs.). Por uma política de ações afirmativas: problematizações do programa conexões de saberes/UFRGS. Porto Alegre: Ed. UFRGS, 2008.

UNIVERSIDADE FEDERAL DO RIO GRANDE DO SUL. Pró-Reitoria de Graduação. Perfis e representações dos estudantes de graduação da Universidade Federal do Rio Grande do Sul: relatório final. [Organização: José Carlos Ferraz Hennemann e Andrea Benites]. Porto Alegre, UFRGS, 2003.

UNIVERSIDADE FEDERAL DO RIO GRANDE DO SUL. Comissão Permanente de Seleção. Vestibular da UFRGS - processos seletivos anteriores. Disponível em: <http://www.ufrgs.br/coperse> Acesso em: 30 de abr. 2009. 